\title{
Real Time Part Input Control of a Pull Production System by Finding IF-THEN Rules*
}

\author{
Rizauddin RAMLI**, Hidehiko YAMAMOTO** and Jaber ABU QUDEIRI** \\ ** Intelligent Manufacturing Systems Laboratory, \\ Faculty of Engineering, Gifu University \\ 1-1 Yanagido, Gifu-city, 501-1193, Japan \\ E-mail:k3812205@edu.gifu-u.ac.jp
}

\begin{abstract}
This paper considers the part input problem of a production system where two Flexible Transfer Lines (FTLs) consisting of an up-stream production line and a down-stream production line while operating under Just In Time (JIT) production management. The up-stream production line processes the raw material after receiving them from suppliers, and after processing them, delivers the processed product to a down-stream production line via a conveyer. In this paper, we have proposed a novel idea for a part input real time control system, known as Algorithm for Real Time Control of Part Input Systems (ARTCOPS). The algorithm is useful when FTLs are in operation under a production order that is different from the pre-decided production schedule. Simulations of virtual production systems have been carried out to verify that ARTCOPS is useful in real time control, although the production orders are different from the pre-decided production scheduling.
\end{abstract}

Key words: Flexible Transfer Lines, Real Time Control, IF-THEN Rules, Just In Time, Pull Production System

\section{Introduction}

Today, the processing of multiple type parts and assembling are performed by many production lines. One of the mass production styles that produce multiple type parts is Flexible Transfer Lines (FTLs). Often, many FTLs operate under the Just In Time (JIT) production policy in conditions where each of the FTLs are linked together. The conceptual JIT production policy is defined as "the basis of the Toyota production system in which the right parts are needed in the assembly line at the time they are needed, and only in the amount needed" to achieve "the absolute elimination of waste" (1).

A JIT production system is a pull production system, in which the most well known is called the Kanban (instruction card) system ${ }^{(2),(3),(4)}$. In other words, the down-stream production line informs the up-stream production line of the needed types and amount of parts beforehand. For instance, a parent company makes a weekly pre-decided production schedule of certain parts (such as 3000 pieces of part A, 2500 pieces of part B ...etc.), in advance. Normally, the up-stream production line will schedule the part input to the production line based on the pre-decided production schedule.

Pull production systems are most successful in production environments with stable demand and lead times ${ }^{(5),(6)}$. Unfortunately, when a company experiences wide variations in supply and demand from customers, the pre-decided production schedule cannot be maintained and is liable to change on the current day. In addition, an adaptive type of pull production system ${ }^{(7)}$ was proposed that monitors the actual inventory levels and adjusts the number of Kanban by releasing and capturing extra Kanban based on customer demands. Moreover, Gold ${ }^{(8)}$ studied a sophisticated batch service system in a push and pull 
manufacturing environment by using embedded Markov chain techniques. However, most of these studies only focus on a single stage system or single-product Kanban system. A mathematical method and simulation approach of offline pre-decided production scheduling has also been proposed ${ }^{(9),(10)}$. Furthermore, a reactive JIT ordering system ${ }^{(11)}$ for multi-stage production systems with unstable changes in demand was also proposed.

However, a pre-decided production schedule is not effective if the demands from the preceding process are different from the actual schedule. In this paper, we propose a real time control of part input scheduling algorithm called Algorithm for Real Time Control of Parts Input System (ARTCOPS). This is based on JIT with pull production systems where 2 FTLs are linked together via a conveyer. In the algorithm, each state of the delivered parts on the conveyer from the up-stream production line to the down-stream production line is observed in real time, providing a feedback for part input at the up-stream production line entrance. We adopt ARTCOPS to a virtual production system to verify that it will not negatively affect the down-stream production line, even though the actual demands from the down-stream production line are different from the pre-decided schedule.

\section{Production System Model}

The production model that we consider in this paper is shown in Fig.1. This model considers a production system that consists of 2 types of production lines: the up-stream production line and down-stream production line. Our production system is operated under the condition of a sort of Kanban system or one by one production. In Fig. 1, the Kanban is used at the bay of the up-stream production line and the exit of the down-stream production line. Both lines are linked by a conveyer (CONV) and operate together as a single production line. This can be analogous to a company with 2 factories, where the down-stream production line represents a factory at the parent company and the up-stream production line represents another factory. Since both production lines are linked, the down-stream production line will stop if no parts are supplied by the up-stream production line on the conveyer. However, if both production lines manage to operate efficiently, it is possible to realize an unnecessary inventory production system. As a result, an effective production system can be achieved since the up-stream production line will be able to supply the needed parts to the down-stream production line without any delay.

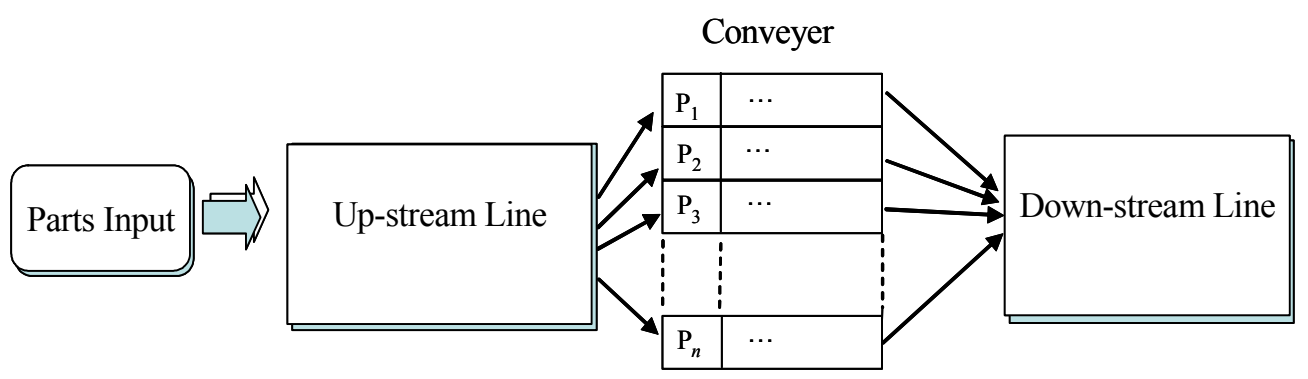

Fig.1 Model of Production system

Furthermore, the pull production system considered in this paper will focus on a one by one parts input production system. In the production system, the down-stream production line removes one part from the conveyer and one part will be input to the bay of the up-stream production line ${ }^{(12)}$. Accordingly, in the one by one parts input production system, the down-stream production line demands the required part from the up-stream production line based on the pre-decided daily production schedule. However, the pre-decided daily production schedule can be disrupted due to the unavoidable existence of unpredictable 
failure at the down-stream production line such as a machining defect, urgent job, etc. Additionally, sometimes the down-stream production line may fail to immediately relate these changes to the up-stream production line. On the other hand, parts machining defects and reprocessing jobs that occasionally occur at the up-stream production line discharge the parts from the production line, causing a non-sequential supply phenomenon to the down-stream production line. Thus, the unstable changes of parts demands from the down-stream production line and the non-sequential supply from the up-stream production line are unavoidable. Hence, it will affect the operation rates of the production system itself.

\section{Real Time Control of Pull Production System}

\subsection{Problems Statement}

In the case where two production lines are linked and operate as a single production line, it is difficult to implement a pre-decided production schedule. This is due to the difference between parts demands from the down-stream production line and the actual pre-decided production schedule. Solving this problem necessitates a real time control of parts input to the bay of the up-stream production line, and is based on the prediction of a pull production system of the down-stream production line during operation. This prediction is extremely crucial because of the unclear information of what will be removed by the down-stream production line.

Consequently, in this paper, we propose ARTCOPS; analogical rules of real time control that operate on the basis of a one by one parts' order lined up on the CONV. The outline of ARTCOPS is shown in Fig.2 where the parts order on the CONV from the up-stream production line is associated with the parts input to the bay of the up-stream production line by using IF-THEN rules. In other words, we can express the relations of a one by one parts' order on the CONV and parts input rules by using IF-THEN rules. Here, we define the actual parts' order on the CONV while the production line is running as a TRUTH part. Thus, by collating the IF-THEN rules and the TRUTH part, it is possible to perform a real time control of a pull production system.

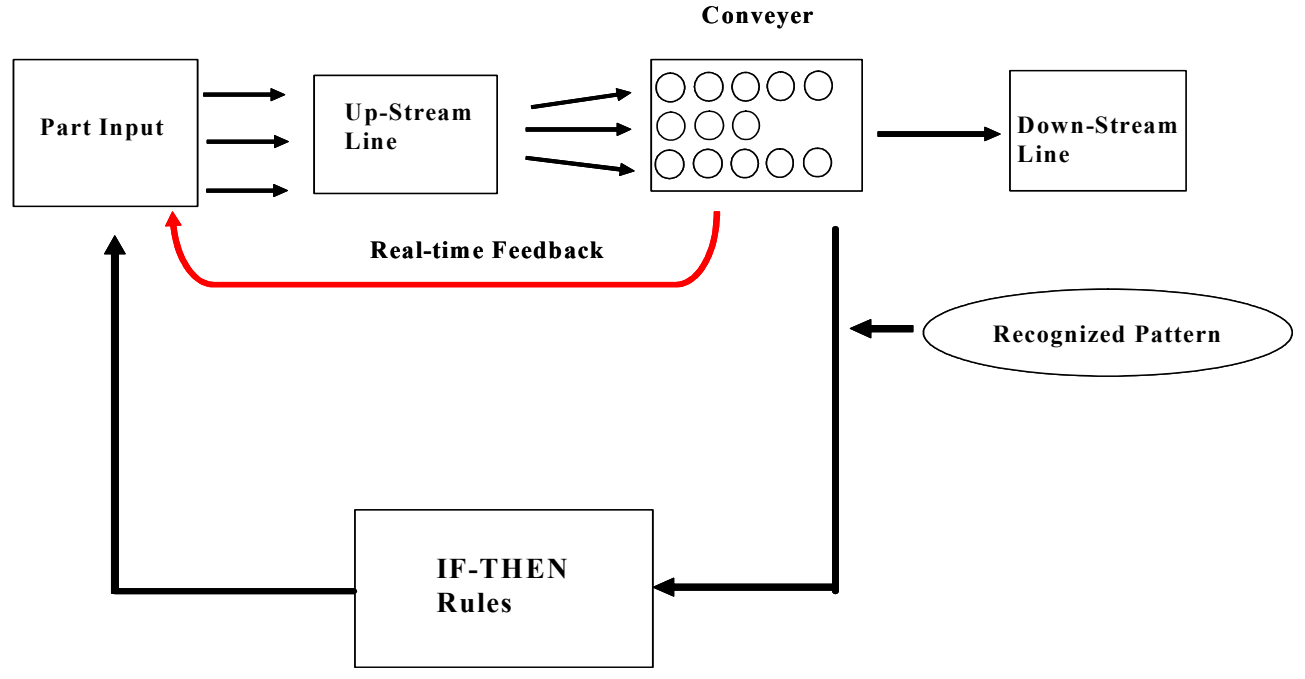

Fig.2 Outline of ARTCOPS

Even though many of the scheduling problems in a production system that use real time control systems have attracted many researchers (13), (14), (15), (16), most have not employed any feedback method of real time production control such as we have adopted in ARTCOPS, where the number of parts on the CONV is counted as output value with the multiple disordered IF-THEN rules collated together. Furthermore, the pull production 
system with ARTCOPS is not simply a feasible system due to the following two points of difficulties. First, the parts' orders on the CONV consist of multiple combinations, resulting in the creation of multiple IF-THEN rules. For instance, a production system that processes $n$ types of parts with the capacity of parts that can be lined up on the CONV as $b$ pieces, then it will have $(b+1)^{n}$ combinations. Therefore, $(b+1)^{n}$ IF-THEN rules have to be created. As an example, in the case where $n=5, b=6$, there are 16,807 combinations of parts' order on the CONV, meaning 16,807 IF-THEN rules have to be created. An approach to reduce the multiple combinatorial problems such as evolutionary classifier (17), (18), (19), (20) is unsuitable for implementation due to the huge combinations required for large calculation times to encode the individuals. A tree search-based algorithm ${ }^{(21),(22),(23)}$ is another approach for handling this problem, but it is difficult to employ because making a correct tree construction is difficult for our production problem.

The second difficulty relates to the constant search for accurate IF-THEN rules. From the parts input in the up-stream production line to the parts transferred to the CONV, delay times exist between these periods. Furthermore, many parts are discharged from the production line occasionally due to machining defects which leads to unclear conditions of parts that line up on the CONV. Because of this, the relationship between the parts' order on the CONV and the parts input in the up-stream production line no longer associates as a one-to-one correspondence. It means there is no guarantee that each IF-part will correspond with one THEN-part.

\subsection{Out-pattern Concept and Parts Input Rules}

In order to reduce the large numbers of IF-THEN rules, we propose an Out-pattern concept where smaller numbers rather than the numbers of parts' order on the CONV $(b+1)^{n}$ are adopted. It means that the parts' order on the CONV are limited to $m$ pieces ( $m \ll$ $\left.(b+1)^{n}\right)$. Each $m$ piece of the parts' order are expressed by Out-pattern $\mathrm{O}_{\mathrm{p}}(m)$. In other words, the Out-patterns are configured as an alternative expression of the multiple parts' order that are lined up on the CONV.

By using this concept, ARTCOPS describes the parts input rules as follows: the Out-pattern concept for the IF-part and parts input for the THEN-part. Hence, $m$ pieces of Out-pattern $\mathrm{O}_{\mathrm{p}}(m)$ which is far less than the actual part's order numbers $(b+1)^{n}$ is adopted as an alternative. Furthermore, for each parts' order that actually lines up on the CONV $(b+1)^{n}$, one Out-pattern then corresponds to more than one possible part input. An example is shown in Fig.3, where one IF-part of Out-pattern $\mathrm{O}_{\mathrm{p}}(1)$ corresponds to q pieces of THEN-part for the part inputs.

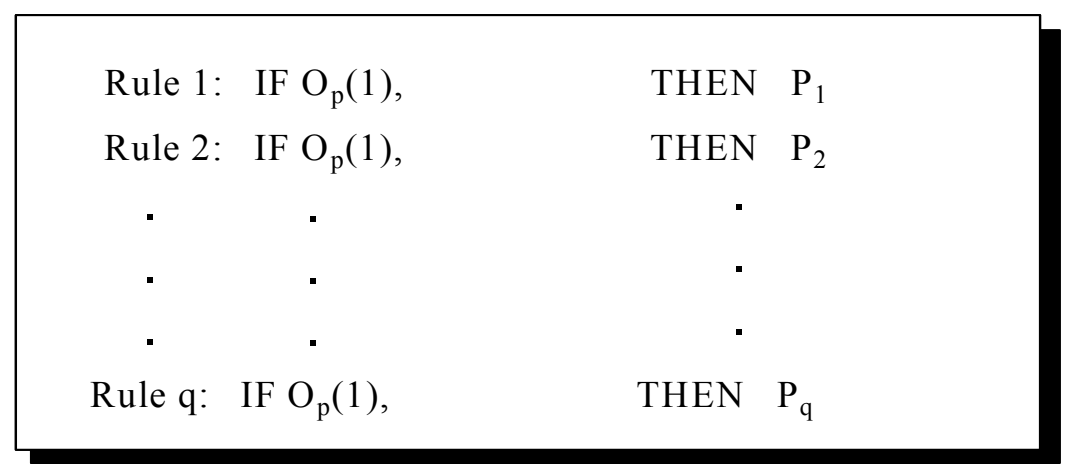

Fig.3 Example of IF-THEN rules 


\subsection{Algorithm of ARTCOPS}

In ARTCOPS, the actual parts' order that line up on the CONV are defined as facts that collate with the IF-part of the Out-pattern concept. The collated rules associate with the THEN-part during the analogy process. A real time control of ARTCOPS is performed where the analogy process is repeated in any arbitrary time interval during the actual production system run time. The algorithm of the analogy process is shown below. Before the algorithm is formulated, the notations used are included as follows.

\section{[Notations]}

$\mathrm{P}_{n} \quad$ Parts' order that represents the part which is actually lined up on the CONV in order.

$\operatorname{Num}\left(\mathrm{P}_{n}\right) \quad$ Number of parts' orders $\mathrm{P}_{n}$.

$\mathrm{S}_{\text {fact }} \quad$ Set where the numbers of parts' orders $\operatorname{Num}\left(\mathrm{P}_{n}\right)$ are used as elements. $\mathrm{S}_{\text {fact }}$ is expressed as follows.

$\mathrm{S}_{\text {fact }}=\left\{\operatorname{Num}\left(\mathrm{P}_{1}\right), \operatorname{Num}\left(\mathrm{P}_{2}\right), \cdots, \operatorname{Num}\left(\mathrm{P}_{n}\right)\right\}$

$\mathrm{M} \quad$ Number of Out-pattern.

$\mathrm{O}_{\mathrm{p}}(m) \quad$ The Out-pattern is described as the set of number of $n$ types of parts that are virtually lined up on the CONV. The elements of the set are selected randomly from $n$ arbitrary positive integers.

$\mathrm{O}_{\mathrm{p}}(m)=\{\operatorname{rand}(1), \operatorname{rand}(2), \operatorname{rand}(3), \cdots, \operatorname{rand}(n)\}$

$\mathrm{O}_{\text {set }} \quad$ Set that consists of $m$ Out-pattern $\mathrm{O}_{\mathrm{p}}(m)$ as the elements.

$\mathrm{O}_{\text {set }}=\left\{\mathrm{O}_{\mathrm{p}}(1), \mathrm{O}_{\mathrm{p}}(2), \mathrm{O}_{\mathrm{p}}(3), \cdots, \mathrm{O}_{\mathrm{p}}(m)\right\}$

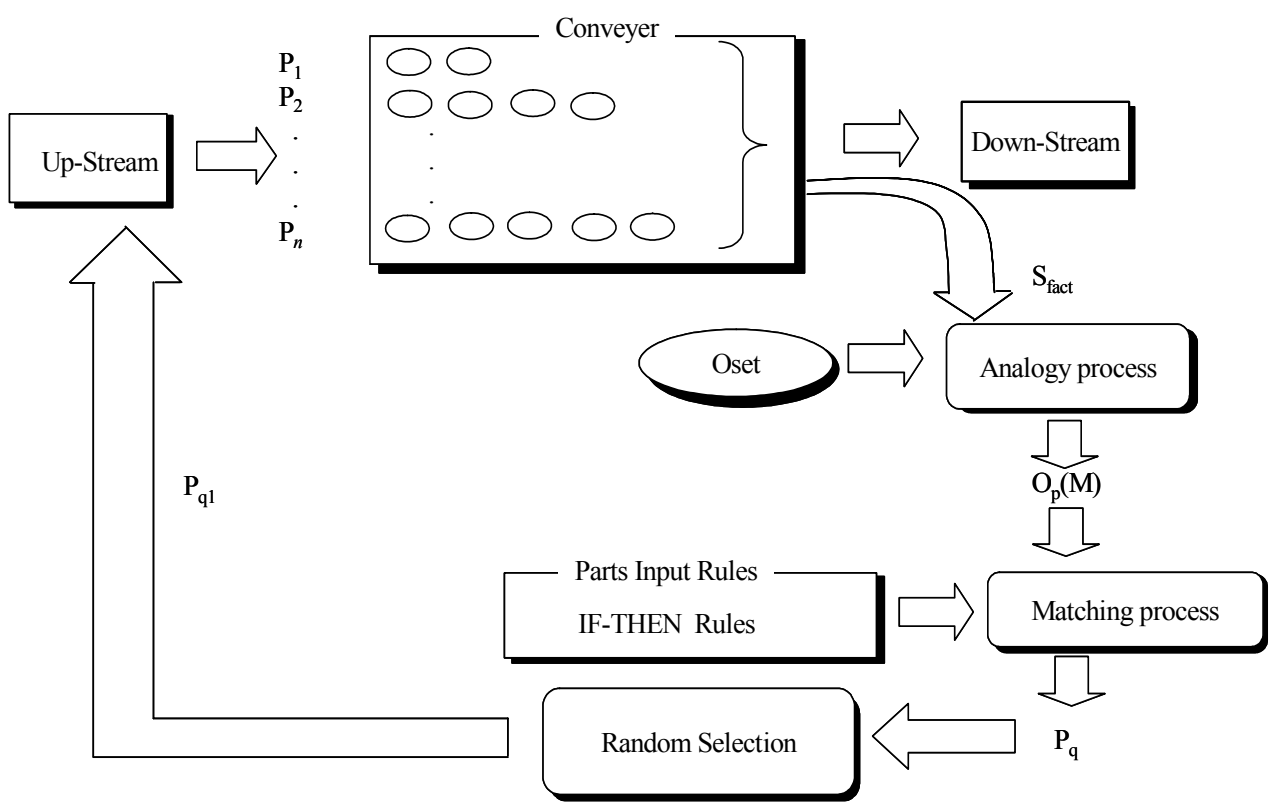

Fig.4 Schematic diagram of ARTCOPS concept

\section{[Algorithm of Analogy Process]}

STEP1: Calculate the number of parts' order Num $\left(\mathrm{P}_{n}\right)$ of each part $\mathrm{P}_{n}$ that are lined up on the CONV and generate the set of parts' order numbers $\mathrm{S}_{\text {fact }}$.

STEP2: Collate between each element of Out-pattern set $\mathrm{O}_{\text {set }}$ and the set of parts' order numbers $S_{\text {fact. }}$. Select the Out-pattern that is the most similar to the $S_{\text {fact }}$ and set as $\mathrm{O}_{p}(M)$.

STEP3: Compare the most similar Out-patterns $\mathrm{O}_{\mathrm{p}}(\mathrm{M})$ and the IF-part of parts input rules, select all the parts input candidates that have the same rules with the IF-part. Set the candidates as $\mathrm{P}_{\mathrm{q}}$. 
STEP4: Randomly select one part $\mathrm{P}_{\mathrm{q} 1}$, from the overall $\mathrm{P}_{\mathrm{q}}$. Then, $\mathrm{P}_{\mathrm{q} 1}$ is set as the input part.

The conceptual diagram of ARTCOPS is illustrated in Fig.4. In the algorithm, the Out-pattern most similar to the parts that are lined up on the CONV is defined as $\mathrm{O}_{\mathrm{p}}(\mathrm{M})$ and one part input candidate $\mathrm{P}_{\mathrm{q} 1}$ is selected from the multiple parts input candidates $\mathrm{P}_{\mathrm{q}}$ that associate with $\mathrm{O}_{\mathrm{p}}(\mathrm{M})$. In other words, although the same Out-pattern is selected, with this characteristic algorithm, the chance for the same part to be input can be avoided. Next, to solve the difficulty of constant search for the right IF-THEN rules, one THEN-part is selected from the multiple IF-THEN rules which simultaneously correspond to the production condition. Thus, the second problem can be solved by adopting the IF-THEN rules that include one Out-pattern and multiple parts input candidates.

\section{Creation of IF-THEN Rules for Parts Input}

\subsection{Creation of IF-part}

In ARTCOPS, the IF-part of the parts input rules are carried out by using the Out-pattern concept. With the Out-pattern concept, the $(b+1)^{n}$ pieces of parts conditionally lined up on the CONV are reduced to $m$ pieces by using an alternative method. The generation of the algorithm for the Out-pattern concept is shown in the flowchart in Fig. 5.

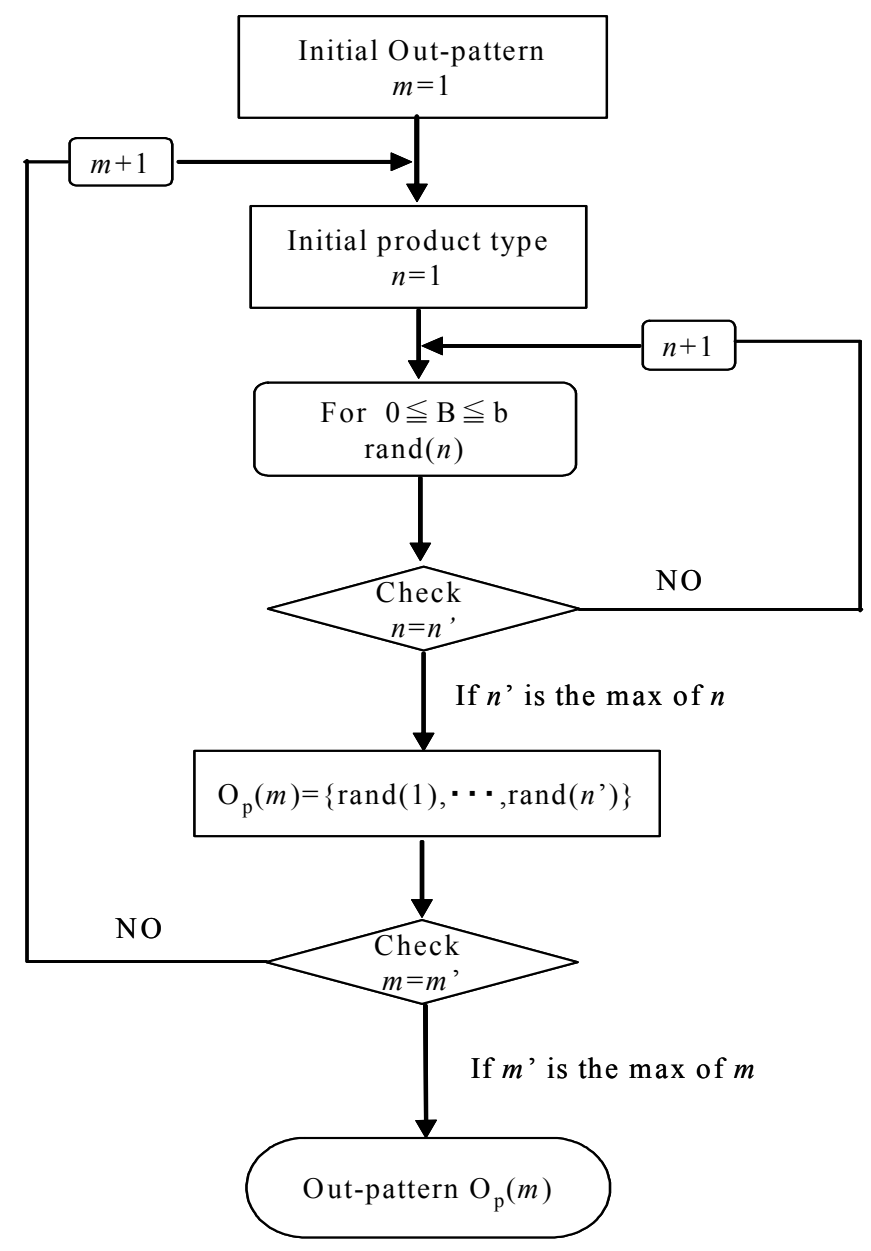

Fig.5 Flowchart of IF part creation

By using the algorithm, we can generate the number of Out- pattern $\mathrm{O}_{\mathrm{p}}(m)$ randomly. 


\subsection{Creation of THEN-part}

The THEN-part of the parts input rule describes how each Out-pattern is collated with the parts that will be input to the bay of the up-stream production lines. It can generally be expressed as,

IF the parts' order condition that line up on the CONV is the same as $\mathrm{O}_{\mathrm{p}}(m)$, THEN put $\mathrm{I}_{1}$ or $\mathrm{I}_{2}, \cdots$.

where, $I_{1}, I_{2}, \cdots$ are assumed as pseudo input part candidates. It is undesirable to arbitrarily select pseudo input part candidates from the existing multiple input part candidates. The reason is because for each condition of $\mathrm{O}_{\mathrm{p}}(m)$, there exists a part that should either be input or not. Consequently, ARTCOPS selects the $c$ pieces of the pseudo input part candidates as $\mathrm{I}_{c}$ based on these following 5 standards.

[STANDARD1] For any parts' order condition in $\mathrm{O}_{\mathrm{p}}(\mathrm{m})$, if the part that lines up does not exist, then this part is considered as one element of $\mathrm{I}_{c}$.

[STANDARD2] For any parts' order condition in $\mathrm{O}_{\mathrm{p}}(\mathrm{m})$, if the part satisfies the following rules, then this part is considered as one element of $\mathrm{I}_{c}$.

$$
\operatorname{Opt}(n)-\mathrm{Num}\left(\mathrm{P}_{n}\right) \geqq d
$$

( $d$ is denoted as an arbitrary positive integer.)

[STANDARD3] For any parts' order in $\mathrm{O}_{\mathrm{p}}(m)$, if the parts that line up do not reach the desired value $\operatorname{Opt}(n)$, then this part is considered as one element of $\mathrm{I}_{c}$.

[STANDARD4] For any parts` order in $\mathrm{O}_{\mathrm{p}}(m)$, if the part satisfies the following rules, then this part is considered as one element of $\mathrm{I}_{c}$.

$$
\operatorname{Num}\left(\mathrm{P}_{n}\right)-\operatorname{Opt}(n) \leqq d^{\prime}
$$

( $d$ ' is denoted as an arbitrary positive integer.)

[STANDARD5] All parts are considered as one element of $\mathrm{I}_{c}$.

Here, $d$ in [STANDARD2] and $d$ ' in [STANDARD4] represent the minimum number and the maximum number of parts that are lined up on the CONV, respectively. These 5 standards indicate the priority of the input part which is judged based on the parts' order condition on the CONV.

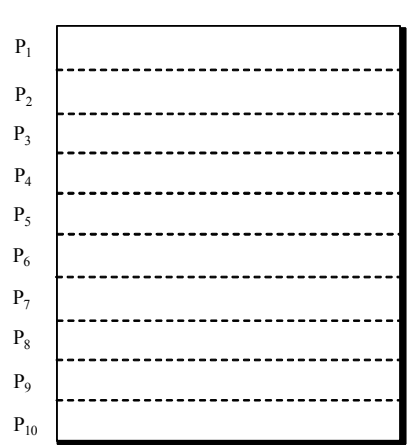

(a)

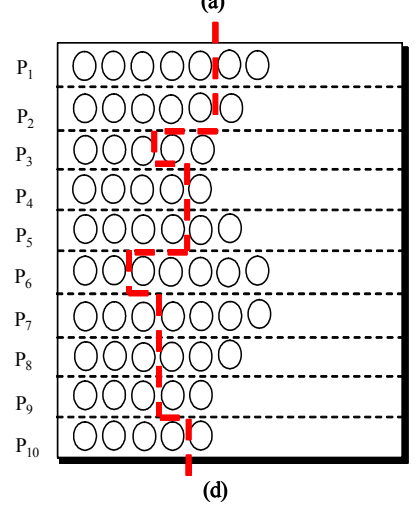

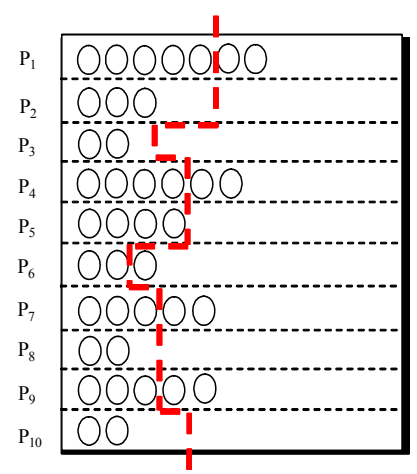

(b)

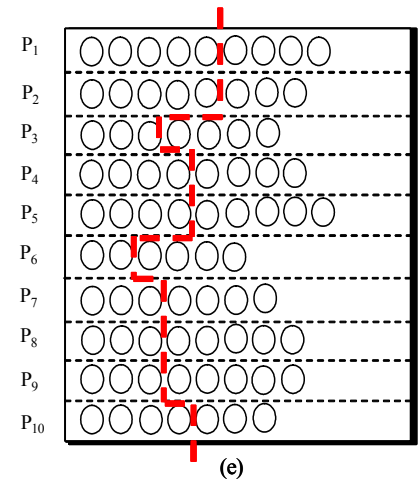

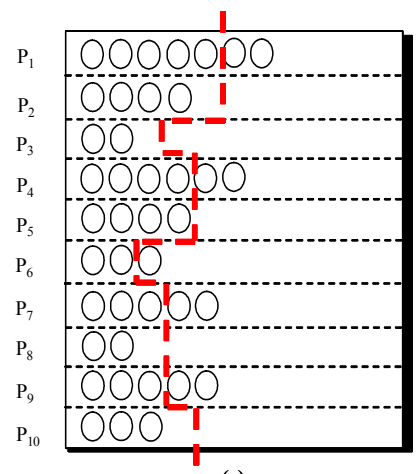

(c)

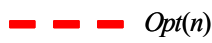

Fig.6 Examples of [STANDARD1] [STANDARD5] 
For example, [STANDARD1] assumes the highest priority to be the input part because no part is lined up on the CONV, followed by [STANDARD2]. According to these standards, it is undesirable to select a different part as the pseudo input part candidates $\mathrm{I}_{c}$. Therefore, these 5 standards have a triage from [STANDARD1] $\rightarrow$ [STANDARD5] sequentially, where the element of $\mathrm{I}_{c}$ is searched from [STANDARD1], and if the element is found, then the searching is terminated.

Consequently, the desired value $\operatorname{Opt}(n)$ is expressed as the number of parts that corresponds to the target production ratio of the pre-decided production schedule. Since the target of the production ratio can be expressed as $r(1): r(2): \cdots: r(n)$, by using the common factor $R, \operatorname{Opt}(n)$ is given as follows.

$$
\operatorname{Opt}(n)= \begin{cases}\frac{r(n)}{R} & \left(\text { where, } \frac{r(n)}{R} \leq b\right) \\ b & \left(\text { where }, \frac{r(n)}{R}>b\right)\end{cases}
$$

Figure $6(\mathrm{a}) \sim(\mathrm{e})$ illustrate the examples of these 5 standards respectively. In every figure, $d=d^{\prime}=2$ and $\mathrm{P}_{1} \sim \mathrm{P}_{10}$ are the conditions of the part lined up on the CONV. Figure 6(a) shows a condition of [STANDARD1] where there are no parts lined up on the CONV. In this case, each part $\mathrm{P}_{1} \sim \mathrm{P}_{10}$ can be selected as elements of $\mathrm{I}_{c}$. Similarly, Fig.6(b) shows the condition of [STANDARD2]. In this case, since the difference between the desired $\operatorname{Opt}(n)$ and the number of parts lined up on the CONV are 2 pieces, part $\mathrm{P}_{2}$ and $\mathrm{P}_{10}$ can be selected as elements of $\mathrm{I}_{c}$. Next, Fig.6(c) shows the condition of [STANDARD3] where part $\mathrm{P}_{2}, \mathrm{P}_{3}, \mathrm{P}_{8}$ and $\mathrm{P}_{10}$ are selected as elements of $\mathrm{I}_{c}$ because these kinds of parts which are being lined up on the CONV have not achieved the desired $\operatorname{Opt}(n)$. Figure 6(d) shows the condition of [STANDARD4]. In this case, the difference between parts that are lined up on the CONV and $\operatorname{Opt}(n)$ which are less than 2 pieces can be selected as elements of $\mathrm{I}_{c}$, i.e., $\mathrm{P}_{1}, \mathrm{P}_{2}, \mathrm{P}_{3}, \mathrm{P}_{4}$, $\mathrm{P}_{5}, \mathrm{P}_{9}$ and $\mathrm{P}_{10}$. Lastly, Fig.6(e) shows the condition of [STANDARD5], where all parts can be selected as parts input candidate $\mathrm{I}_{c}$.

In this way, the IF-THEN rules of parts input can be described by using the Out-pattern concept for IF part, and the THEN part is associated with the pseudo-part input candidate based on these 5 standards. As it stands now, even an experienced supervisor of the production line will face a major problem due to the huge combinations of the parts order, however, by using our proposed IF-THEN rules that are based on the Out-pattern concept and the pseudo-part input candidate based on the 5 standards will enable him to be able solve any production scheduling problems.

\section{Virtual Production}

\subsection{Virtual Production System}

In order to confirm the effectiveness of ARTCOPS, we constructed a virtual production system consisting of up-stream and down-stream production lines that were linked to each other and ran a simulation program. We applied the developed real time control of parts input scheduling algorithm ARTCOPS once every 15 minutes to the virtual production system. The virtual production system consisted of an automated production system that produced 10 types of different parts $\mathrm{P}_{1}, \mathrm{P}_{2}, \cdots, \mathrm{P}_{10}$. The production ratios of the pre-decided production schedule of each part were set as, $\mathrm{P}_{1}: \mathrm{P}_{2}: \cdots: \mathrm{P}_{10}=3: 6: 4: 3: 5: 2: 3: 3$ : $4: 6$, respectively. Furthermore, there were 120 processes at the up-stream production line; with the desired machining time for each process set at 15 seconds. The maximum number of each type of parts that were able to be lined up on the CONV that carried the complete parts was 7 pieces. Therefore, $b=7$. Also, in this virtual production system simulation, the 
number of parts types were 10 types, so $n=10$. In this way, we could express the total $8^{10}$ pieces of parts lined up conditionally on the CONV as $m=100$ Out-pattern.

Sometimes some parts would be discharged from the production line due to several aspects, such as machining defects that occurred at the up-stream production line. The parts were randomly discharged as follows: for every 150 pieces of parts that were input to the up-stream production line, one piece was randomly selected as a machining defect that would be discharged from the up-stream production line. Moreover, at the down-stream production line, a small machine breakdown occurred once every 2250 seconds causing the line to stop for 30 seconds. During the line stop, parts on the CONV remained on it. In additional, the down-stream production line was set to pick up arbitrary parts from the CONV every 15 seconds.

\subsection{Simulation of Virtual Production System}

In the virtual production system, the production periods were 40 hours, that is, one 8 hour day for 5 production days. In order to generate a production system that was different from the pre-decided production schedule, the production order was changed as follows: first, the down-stream production line would pick up the parts from the CONV according to the pre-decided production schedule, and then, after 40 pieces, it would start to pick up a different type of part. The changes in the rules of the parts pick up rule are given as follows. $<\boldsymbol{C H A N G E} \mathbf{1}>$ For every 8 times, the parts pick up rule will change once from the pre-decided schedule.

$<\boldsymbol{C H A N G E} 2>$ For every 6 times, the parts pick up rule will change once from the pre-decided schedule.

$<$ CHANGE 3> For every 4 times, the parts pick up rule will change once from the pre-decided schedule.

$<\boldsymbol{C H A N G E} 4>$ For every 2 times, the parts pick up rule will change once from the pre-decided schedule.

$<$ CHANGE $5>$ The parts pick up rule will change each time from the pre-decided schedule. The parts pick up rules are different from the pre-decided production schedule sequentially from $<$ CHANGE $1>\rightarrow<$ CHANGE $5>$.

\subsection{Result of Virtual Production System}

We ran the simulation by using 10 random number groups, each of which corresponded to 10 times of the virtual production system. The average output of parts that were picked up by the down-stream production line is shown in Table 1. Furthermore, a conventional method which only uses the pre-decided production schedule without any real time control was performed in order to compare with the ARTCOPS result. Similarly, Fig.7 shows the virtual production result of the 10 random number groups. The vertical axis represents the quantity of production while the horizontal axis represents the change of the part pick up rule.

Based on the results in Table 1, ARTCOPS demonstrates that although the parts pick up rules were changed from $\langle$ CHANGE $1>\rightarrow<$ CHANGE $5>$, the supplies of output to the down-stream production line did not decrease even though the production commands were different from the pre-decided production schedule.

Contrarily, the results of the conventional method shows that the production outputs to the down-stream production line decreased dramatically. In this way, it can be ascertained that by using ARTCOPS, even if the production demand from the down-stream to up-stream production lines are different from the pre-decided production schedule, ARTCOPS can 
manage to overcome this problem and create no bottlenecks to the down-stream production line.

Table 1 Average output parts number

\begin{tabular}{|c|c|c|}
\hline $\begin{array}{l}\begin{array}{c}\text { Papid Job } \\
\text { Conditions }\end{array} \\
\text { to Dw-stream line }\end{array}$ & ARTCOPS & $\begin{array}{c}\text { Conventional } \\
\text { Method }\end{array}$ \\
\hline$<C H A N G E 1>$ & 7294.3 & 7185.7 \\
\hline$<C H A N G E 2>$ & 7327.3 & 7060.4 \\
\hline$<C H A N G E 3>$ & 7343.1 & 6882.0 \\
\hline$<C H A N G E 4>$ & 7307.7 & 6231.0 \\
\hline$<$ CHANGE $5>$ & 7337.3 & 3531.4 \\
\hline
\end{tabular}

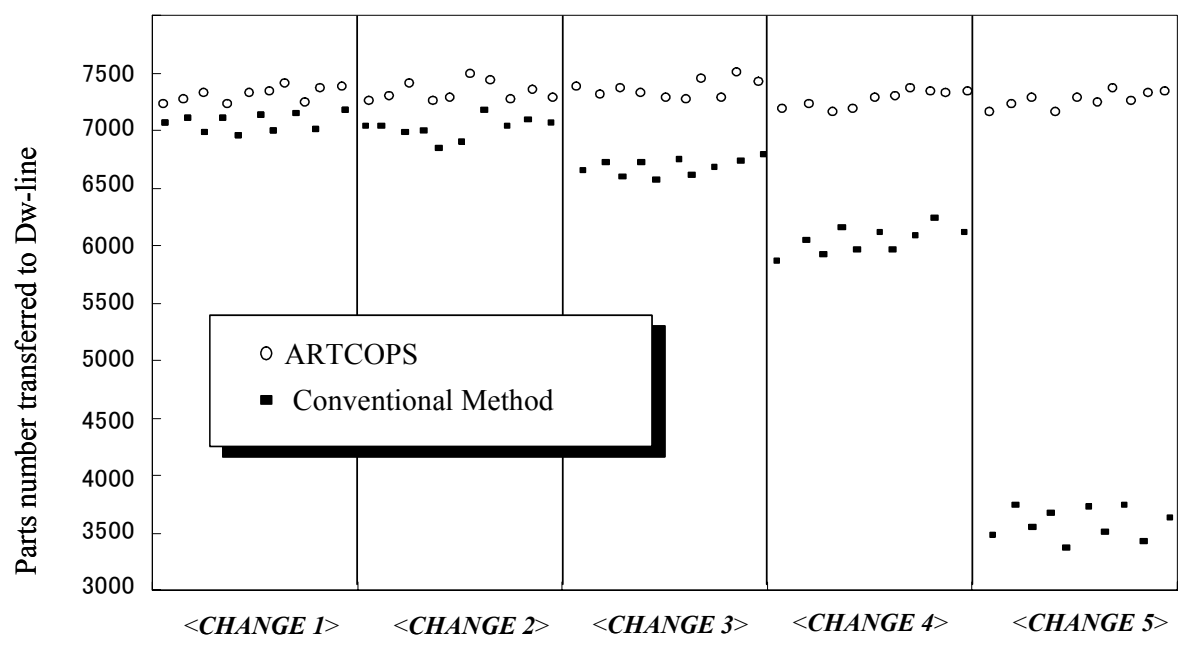

Fig.7 Simulation results

\section{Conclusions}

In this paper, we described the development of real time control of part input based on the pull production system that is typical of a JIT production system. In the control system ARTCOPS, the parts' order on the CONV are observed one by one, and simultaneously by collating with multiple IF-THEN rules, the part input can be decided on a one by one production system. ARTCOPS can maintain stable production yields even though the production demands from the down-stream production line are different from the pre-decided production schedule. By using these results, it can be ascertained that our proposed real time part input algorithm, which uses the Out-pattern concept collated to the IF part in the analogy process and the selection of part input with the THEN part, are efficiently implemented.

\section{References}

(1) Ohno, T., "Toyota Production System: Beyond Large-Scale Production", Productivity Press, 1988.

(2) Kimura, O. and Terada H., "Design and analysis of pull production system: A method of multi-stage production control" International Journal of Production Research, Vol. 19, No. 3, pp241-253, 1981.

(3) Markham, I.S., Mathieu, R.G. and Wray, B.A, "A rule induction approach for determining the number of kanbans in a just-in-time production system", Computers \& 
Industrial Engineering, Vol. 34, No. 4, pp717-727, 1998.

(4) Schonberger, R.J., "Japanese Manufacturing Techniques: Nine Hidden Lessons in Simplicity", Free Press, New York, 1982.

(5) Hitomi, K., "Manufacturing Systems Engineering: A Unified Approach to Manufacturing Technology, Production Management, and Industrial Economics", Second Edition, Taylor \& Francis, London, 1996.

(6) Monden, Y., "Toyota Production System : An Integrated Approach to Just-In-Time", Third Edition, Engineering and Management Press, 1998.

(7) Tardif, V. and Maaseidvaag, L., "An adaptive approach to controlling kanban systems", European Journal of Operational Research, Vol. 132, No. 2, pp411-424, 2001.

(8) Gold, H. and Tran-Gia, P., "Performance analysis of batch service queue arising out of manufacturing system modelling", Queuing Systems, Vol.14, pp413-426, 1993

(9) Baykoc, O.F. and Erol, S., "Simulation modeling and analysis of a JIT production system", International Journal of Production Economics, Vol. 55, pp203-212, 1998.

(10) Mattfeld, D.C., Bierwirth, C. and Kopfer, H., "A search space analysis of the job shop scheduling problem", Annals of Operations Research, Vol. 86, pp441-453, 1999.

(11) Takahashi, K., Morikawa, K., and Nakamura, N., "Reactive JIT ordering system for changes in the mean and variance of demand", International Journal of Production Economics, Vol. 92, No. 2, pp181-196, 2004.

(12) Yamamoto, H., "One-by-One Parts Input Method by Off-line Production Simulator with GA", European Journal of Automation, Hermes Science Publications, Eds. A. Artiba, pp1173-1186, 2000.

(13) Hatono, I., Yamagata, K. and Tamura, H., "Modeling and On-Line Scheduling of Flexible Manufacturing Systems Using Stochastic Petri Nets", IEEE Trans. on Software Eng. , Vol. 17, No. 2, pp126-132, 1991.

(14) Julia, S. and Valette, R., "Real time scheduling of batch systems", Simulation Practice and Theory, Vol. 8, No. 5, pp307-319, 2000.

(15) Qiu, R., "Virtual production line based WIP control for semiconductor manufacturing systems", International Journal of Production Economics, Vol. 95, No. 2, pp165-178, 2005.

(16) Fowler, J.W., Philips, D.T and Hogg, G.L., "Real-time control of multi-product bulkservice semiconductor manufacturing process", IEEE Transactions on Semiconductor Manufacturing, Vol.5, No2, pp158-163, 1992

(17) Holland, J.H, "Hidden Order”, Addison-Wesley Publishing Company, 1995.

(18) Mitavskiy, B., " Comparing evolutionary computation techniques via their representation", Proceeding of the Genetic Evolutionary Computation Conference (GECCO2003), Springer Berlin /Heidelberg, pp1196-1209, 2003.

(19) Apte, C., Hong, S.J., Hosking, J. R.M. , Lepre, J., Pednault, E. P.D. and Rosen, B. K., "Decomposition of heterogeneous classification problem", Intelligent Data Analysis, Vol. 2, No. 1-4, pp81-96, 1998

(20) Chen, Z., He, Y., Chu, F. and Huang, J., "Evolutionary strategy for classification problems and its application in fault diagnostics", Engineering Applications of Artificial Intelligence, Vol. 16, No. 1, pp31-38, 2003

(21) Perny, P. and Spanjaard, O., "A preference-based approach to spanning trees and shortest paths problems", European Journal of Operational Research, Vol. 162, No. 2, pp584-601, 2005.

(22) Roura, S., "Digital Access to Comparison-Based Tree Data Structures and Algorithms", Journal of Algorithms, Vol. 40, No.1, pp1-23, 2001

(23) Gramm, J., Guo, J., Hüffner, F. and Niedermeier, R., "Automated generation of search tree algorithms for hard graph modification problems", Algorithmica, Vol.39, No.4, pp321-347, 2004 